\title{
Introduction to the Inaugural Issue
}

\section{Mark Williams}

It is a great pleasure to welcome you to the inaugural issue of The Journal of eMedia Studies. We intend this journal to provide an avenue for both traditional and emergent forms of scholarship about electronic media, their histories, and theoretical work related to these media.

Within the issue, you will find new scholarly work that is blind peer-reviewed (the entries labeled as Essays), plus various other entries that help to demarcate the range of materials we will pursue. The essays themselves begin to illustrate some of this latitude: from the analysis of an interactive work by a major figure in documentary and essayistic cinema (Chris Marker); to work on new "literary" forms enabled and afforded by digital media (e-poetry); to on-line scholarship that raises challenges to underlying precepts of disciplinary methodology (Folkvine). The additional, non-peer reviewed materials extend our focus of attention to book and conference reviews, a professional remembrance, an editorial (understood to be the opinions of the author, rather than those of the Editorial Board or of Dartmouth College), and an extended conversation with an esteemed colleague. I am so pleased that our first such conversation is with Horace Newcomb, a founding figure in the development of the study of Popular Culture in the U.S., and Television Studies in particular. We intend to continue and broaden these areas of scholarly attention in subsequent issues.

Along with kindred e-publications in our field--especially the journals Vectors, FlowTV, and In Medias Res--we hope to afford new and expanded opportunities for emergent and established scholars in the fields that comprise and intersect with Media 
Studies. Submissions are welcome, and guidelines for such appear here.

This project has not been a simple or casual undertaking, and there are many people to acknowledge and thank for their cooperation and talent.

The e-journal project was initiated under the auspices of Richard Lucier who, as Librarian of Dartmouth College, worked to realize the digital library as a site of knowledge production rather than a repository of information merely. I remain grateful for his immediate interest and belief in the significance of this endeavor.

John James played the most central administrative role in the genesis of the journal, organizing its infrastructure within the Library and serving as its advocate. He even traveled to a conference with me to help promote the Library's commitment to both new forms of scholarship, and to ensuring that the work that appears is appropriately archived and indexed.

Paul Merchant and Jennifer Kortfelt built the publishing program for the Library, and have implemented web designer Scott Chesnut's elegant schemes and interfaces. There would be no journal without them, and we all appreciate their efforts.

Outside of Dartmouth, the most important advocate and mentor has been Jeremy Butler, whose know-how about digital technology and whose commitment to its implementation for the public good is renowned in the field of Film and Media Studies. Along the first unsteady phases of gestation, Jeremy knew which questions would matter the most, what the best answers would be, and how to negotiate the process toward arriving at those answers.

Jeremy is a member of our extraordinary Editorial Board, whom I thank for their ready assistance and support in making this endeavor move forward.

Much of the credit for physically realizing the texts presented here goes to Matt Stoff ' 07 , who worked with such dedication through much trial and error (typically my error), to edit, format, and make technically publishable most of this first issue. Sonia Schnee and Phil Fazio have made more recent fundamental contributions to this issue.

Thanks to my many friends and colleagues at Dartmouth College, especially The Department of Film and Television Studies (soon to be Film and Media Studies) for favors and encouragements both small and not-so-small. Jeffrey Horrell, the current 
Librarian of the College, has been unfailingly supportive. I am also extremely grateful to David Seaman, current Associate Librarian for Information Management at Dartmouth College Library, who has undertaken this project with keen interest and skill.

Finally, I especially want to recognize and thank our authors, who have not only contributed their excellent scholarship but have also weathered the technical and human foibles we have experienced along the way toward publication. May your examples inspire much subsequent thought and scholarship. The Editorial Board and I very much look forward to this.

Hanover, New Hampshire April, 2008 